\title{
Using Cosmic-Ray Neutron Probes to Monitor Landscape Scale Soil Water Content in Mixed Land Use Agricultural Systems
}

\author{
Trenton E. Franz,, Ammar Wahbi, ${ }^{2}$ Mariette Vreugdenhil, ${ }^{3}$ Georg Weltin, ${ }^{2}$ Lee Heng, \\ Markus Oismueller, ${ }^{3}$ Peter Strauss, ${ }^{4}$ Gerd Dercon, ${ }^{2}$ and Darin Desilets ${ }^{5}$ \\ ${ }^{1}$ School of Natural Resources, University of Nebraska-Lincoln, Lincoln, NE 68583, USA \\ ${ }^{2}$ Soil and Water Management \& Crop Nutrition Subprogramme, Joint FAO/IAEA Division of Nuclear Techniques in Food and \\ Agriculture, International Atomic Energy Agency (IAEA), 1400 Vienna, Austria \\ ${ }^{3}$ Centre for Water Resource Systems, Vienna University of Technology (TU Vienna), 1040 Vienna, Austria \\ ${ }^{4}$ Federal Agency for Water Management, Institute for Land \& Water Management Research, 3252 Petzenkirchen, Austria \\ ${ }^{5}$ HydroInnova LLC, Albuquerque, NM 87106, USA
}

Correspondence should be addressed to Trenton E. Franz; tfranz2@unl.edu

Received 29 October 2015; Accepted 3 February 2016

Academic Editor: Keith Smettem

Copyright (C) 2016 Trenton E. Franz et al. This is an open access article distributed under the Creative Commons Attribution License, which permits unrestricted use, distribution, and reproduction in any medium, provided the original work is properly cited.

\begin{abstract}
With an ever-increasing demand for natural resources and the societal need to understand and predict natural disasters, soil water content (SWC) observations remain a critical variable to monitor in order to optimally allocate resources, establish early warning systems, and improve weather forecasts. However, routine agricultural production practices of soil cultivation, planting, and harvest make the operation and maintenance of direct contact point sensors for long-term monitoring challenging. In this work, we explore the use of the newly established Cosmic-Ray Neutron Probe (CRNP) and method to monitor landscape average SWC in a mixed agricultural land use system in northeast Austria. The calibrated CRNP landscape SWC values compare well against an independent in situ SWC probe network (MAE $=0.0286 \mathrm{~m}^{3} / \mathrm{m}^{3}$ ) given the challenge of continuous in situ monitoring from probes across a heterogeneous agricultural landscape. The ability of the CRNP to provide real-time and accurate landscape SWC measurements makes it an ideal method for establishing long-term monitoring sites in agricultural ecosystems to aid in agricultural water and nutrient management decisions at the small tract of land scale as well as aiding in management decisions at larger scales.
\end{abstract}

\section{Introduction}

An accurate understanding of the spatiotemporal dynamics of near surface soil water content (SWC) is essential for a greater understanding of the surface energy balance [1], the degree of land surface atmospheric coupling $[2,3]$ and improvements in short-term weather forecasting [4]. With respect to water balance, SWC is a key state variable in determining the partitioning of infiltration and surface runoff [5] and thus predicting stream hydrograph response and making optimal water management decisions. Moreover, SWC is a key parameter in helping understand and predicting the timing and severity of natural disasters such as drought $[6-8]$ and landslides $[9,10]$.
Given the importance of SWC observations for understanding energy balance, water balance, and natural disasters, a wide variety of national and state level monitoring networks using point sensors (i.e., Soil Climate Analysis Network, Climate Reference Network, Oklahoma Mesonet, Automated Weather Data Network, etc.) have been established along with remote sensing from airborne (i.e., Airborne Microwave Observatory of Subcanopy and Subsurface) and satellite platforms (i.e., Soil Moisture Ocean Salinity, Soil Moisture Active Passive) [cf. [11]]. However, a significant gap still exists in fully reconciling differences between point observations with remote sensing [12] given the natural heterogeneity [13] and spatial organization SWC fields exhibit [14]. 


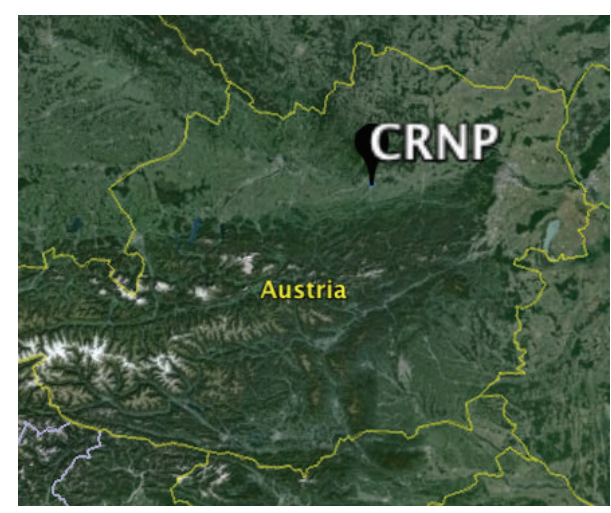

(a)

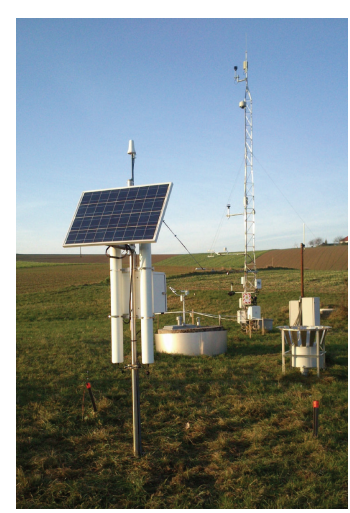

(b)

Figure 1: (a) Location of the Cosmic-Ray Neutron Probe (CRNP) $\left(48.1547^{\circ} \mathrm{N}, 15.1483^{\circ} \mathrm{E}\right)$ within a mixed agricultural land use area in northeast Austria. (b) CRNP located at study site with weather station.

With the unresolved issues between point sensors and remote sensing, and critical spatiotemporal gaps from remote sensing observations, production agriculture has typically relied on direct insertion point based SWC monitoring technologies to aid in decision-making $[15,16]$, albeit with recent acceptance of indirect sensors [17]. A key weakness of direct insertion point sensors in production agriculture is often logistical, as routine management practices of planting, soil cultivation, and harvest make installation and maintenance of point sensor networks costly and time consuming to continuously manage.

In this work, we will explore the use of the indirect Cosmic-Ray Neutron Probe (CRNP) [18] for providing a landscape average SWC value in heterogeneous agricultural landscapes. The CRNP method was recently developed with its main applications in academic research through the establishment of national monitoring networks in the USA [19], Australia [20], UK, and South Africa, with probe installations mostly concentrated in natural ecosystems. Here we will investigate the use of the CRNP in a patchy agricultural landscape with mixed winter and summer crops in northeast Austria and compare the landscape average SWC against an independent in situ Time-Domain Transmissivity (TDT) monitoring network. The landscape average SWC value is critical for aiding in both making optimal management decisions of agricultural water and nutrient application at the parcel scale (i.e., a small tract of land) as well as providing data for larger scale management decisions of flood and drought prediction in human dominated landscapes via data integration with modeling and or early warning systems.

The remainder of the paper is organized as follows. First, we will present an overview of the heterogeneous agricultural land use system and soils of the study site in northeast Austria. Next, we will describe the layout of TDT network and briefly summarize the CRNP method for estimating landscape average SWC. We will then compare the landscape average SWC values between the TDT network and CRNP. Finally, we will discuss practical uses and recommendations of using CRNP in agricultural water management systems for operational use and long-term monitoring.

\section{Study Area}

A CRNP (Model \# CRS 1000/B, HydroInnova LLC, Albuquerque, NM, USA) was installed at the study area in northeast Austria $\left(48.1547^{\circ} \mathrm{N}, 15.1483^{\circ} \mathrm{E}\right.$, elevation $277 \mathrm{~m}$, Figure 1) on December 11, 2013. The study site, Hydrological Open Air Laboratory (HOAL) [21], is a cooperation project between the Federal Agency for Water Management (BAW Petzenkirchen) and the Technical University Vienna (TU Vienna), is located in Petzenkirchen, about $100 \mathrm{~km}$ west of Vienna and receives an annual average $823 \mathrm{~mm}$ of rainfall mostly between April and September. The average annual temperature is $9.5^{\circ} \mathrm{C}$. The research station is located in an undulating agricultural landscape, characterized by Cambisols (56\%), Planosols (21\%), Anthrosols (17\%), Gleysols $(6 \%)$, and Histosols $(<1 \%)$. Infiltration capacities tend to be medium to low, water storage capacities tend to be high, and shrinking cracks may occur in summer due to high clay contents (see Table A1 and Figure 4 in [21]). The main crops are winter wheat, barley, maize, and rape. The land use at the study site consists of various parcel sizes making up a patchwork of different crops. Figure 2(a) illustrates the location of the CRNP and the various land use parcels within the CRNP's measurement area ( $28 \mathrm{ha})$ of a $\sim 300 \mathrm{~m}$ radius circle (see Section 3.1). Table 1 summarizes the 2014 planting, soil cultivation, and harvest dates of 11 of the 12 land use parcels within the study area. For full details of the study site, available datasets, overarching research questions, and specific hypotheses, see [21].

In addition to the weather station and CRNP, a network of Time-Domain Transmissivity (TDT) sensors (SPADE, Julich, Germany) were installed in the second half of 2013. The TDT sensors record hourly SWC at a point and were installed at 31 sites distributed around the study area (Figure 2(b) illustrates the 16 sites within the CRNP measurement area; see Figure 6 in [21] for full details). At each site 4 TDT sensors were installed horizontally at 4 depths (representing soil layers of $\sim 0-5 \mathrm{~cm}, 5-10 \mathrm{~cm}, 15-20 \mathrm{~cm}$, and $45-50 \mathrm{~cm}$ ). Depending on routine agricultural operations and location of the stations, the TDT sensors are removed at various times throughout 


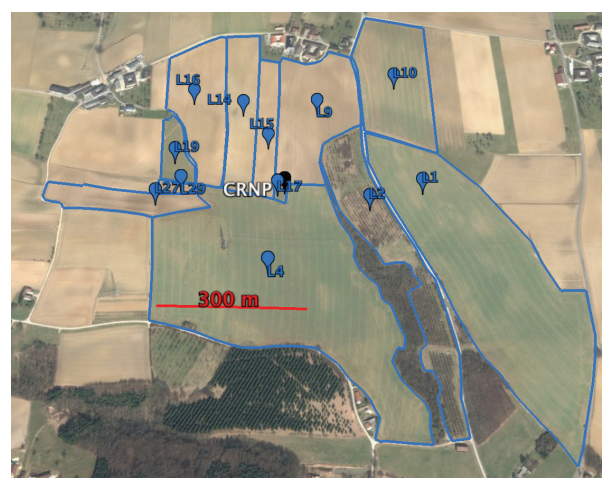

(a)

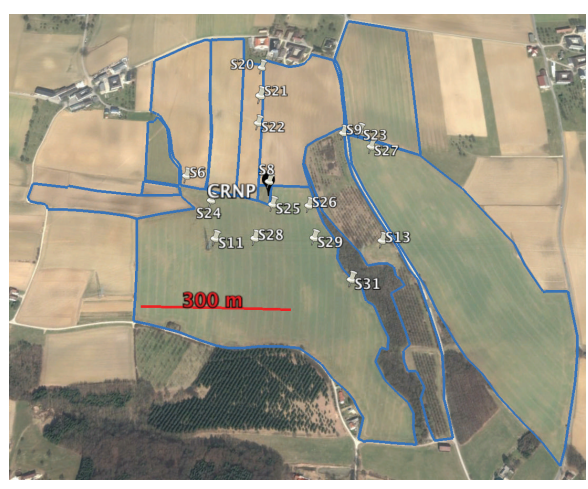

(b)

FIgURE 2: (a) Location of 16 land use parcels within the $300 \mathrm{~m}$ radial CRNP footprint (see Table 1 for planting, soil cultivation, and harvest information). (b) Location of 16 TDT site profiles (probe measurement depths at $0-5 \mathrm{~cm}, 5-10 \mathrm{~cm}, 15-20 \mathrm{~cm}$, and $45-50 \mathrm{~cm}$ ) within the $300 \mathrm{~m}$ radial CRNP footprint.

the year. The TDT sensors are later reinserted for continued monitoring but the full 2014 data were not available. Instead the network of available TDT sensors (between December 12, 2013, and May 1, 2014) were used to independently compare against the CRNP observations of landscape SWC. We note that given the limited distribution of sensors and spatially varying SWC [21] that establishing a "true" landscape average SWC is challenging and a comparison against the CRNP should be framed within the expected uncertainty of the mean given the inherent limitations of "spatial representativeness" of averaging a few point sensors in an area.

\section{Materials and Methods}

3.1. Summary of Cosmic-Ray Neutron Method for Measuring Soil Water Content. The principles and practice of measuring SWC with active source neutrons is well established in soil science and agricultural research $[22,23]$. The passive CRNP measures change in the naturally occurring amount of lowenergy environmental neutrons to quantify changes in landscape SWC $[18,19,24]$. Because the neutron scattering process at these energies $(\sim 1 \mathrm{MeV}$ to $0.5 \mathrm{eV})$ occurs at high velocities $(>10 \mathrm{~km} / \mathrm{s})$ [25], and over tens of meters per collision [26], the effective radius of measurement is around $\sim 240 \mathrm{~m}$ at sea level in dry air [27, 28]. However, the effective CRNP radius is larger at higher elevations (i.e., less air mass means neutrons can travel further during scattering) and smaller with increases in absolute humidity (i.e., more hydrogen in the air reduces travel distance during scattering; see [27] for full details and equations for calculating footprint). Given the elevation of the study site (277 m.a.s.l.) and absolute humidity measurements, the effective CRNP radius will be $\sim 300 \mathrm{~m}$ [27] and will be adopted for this work herein. Similarly, the effective penetration depth of the CRNP varies from $\sim 15 \mathrm{~cm}$ in fully saturated soils $\left(0.40 \mathrm{~m}^{3} / \mathrm{m}^{3}\right)$ to $\sim 75 \mathrm{~cm}$ in pure silica $\left(\mathrm{SiO}_{2}\right)$. Full details of the neutron scattering theory, neutron modeling, and coupling to a physically based unsaturated zone model can be found elsewhere [28, 29]. Given the variable methods used for CRNP calibration and validation (i.e., gravimetric, TDR, TDT), variable individual support volumes of calibration method samples $(\sim 0-20 \mathrm{~cm}$ for TDT and gravimetric and $\sim 0-15 \mathrm{~cm}$ for TDR), variable number of TDT sensors used for landscape average, and primary focus of this work for practical applications, we will assume the CRNP has an effective penetration depth of $\sim 20 \mathrm{~cm}$ for all observed neutron counts. However, we note that the effective depth is dependent on the depth of the calibration dataset used to parameterize the calibration function (see Section 3.2). Full details and sample calculations on horizontal and depth weighting of CRNP are provided elsewhere [28].

\subsection{Conversion of Observed Neutron Counts into Soil Water} Content. The CRNP installed at the site recorded hourly values of moderated neutron counts (counts per hour, $\mathrm{cph})$, atmospheric pressure $(\mathrm{hPa})$, air temperature $\left({ }^{\circ} \mathrm{C}\right)$, and relative humidity (\%) (raw data available in real-time at http:// cosmos.hwr.arizona.edu/Probes/StationDat/087/index.php). The moderated neutron counts were first corrected for location (i.e., neutron scaling factor), incoming highenergy particles, atmospheric pressure, and absolute humidity following established protocols $[19,30]$. The corrected moderated neutron counts were then converted to volumetric pore water content using the calibration function originally proposed by [24] and further modified by [31]. The calibration function is given by

$$
\left(\theta_{p}+\theta_{\mathrm{LW}}+\theta_{\mathrm{SOC}_{\mathrm{eq}}}\right)=\frac{0.0808}{N / N_{0}-0.372}-0.115,
$$

where $\theta_{p}$ is gravimetric water content $(\mathrm{g} / \mathrm{g}), \theta_{\mathrm{LW}}$ is lattice water content $(\mathrm{g} / \mathrm{g}), \theta_{\mathrm{SOC}_{\mathrm{eq}}}$ is soil organic carbon water content equivalent $(\mathrm{g} / \mathrm{g}), N$ is the corrected moderated neutron counts per time interval (cph), and $N_{0}$ is a specific calibrated parameter that represents the count rate over dry silica soils (cph). We note that Soil Water Content (SWC) = volumetric water content, and that SWC $=\theta_{p} *\left(\rho_{\mathrm{b}} / \rho_{\mathrm{w}}\right)\left(\mathrm{m}^{3} / \mathrm{m}^{3}\right)$, where $\rho_{\mathrm{b}}$ is the dry soil bulk density $\left(\mathrm{g} / \mathrm{cm}^{3}\right)$ and $\rho_{\mathrm{w}}$ is the density of water $\left(=1 \mathrm{~g} / \mathrm{cm}^{3}\right)$. Following [32], soil organic 
TABLE 1: Summary of planting, soil cultivation, and harvest date for each land use parcel. Note: no data was available for land use in parcel 1 (see Figure 2(a)).

\begin{tabular}{|c|c|c|c|c|c|c|}
\hline Land use parcel & TDT Site & Date & Action & Description & Amount & Units \\
\hline 1 & 27 & NA & NA & NA & NA & NA \\
\hline 2 & \multirow{5}{*}{9,13} & $7 / 30 / 14$ & Harvest & Straw left on field (mulching) & 3500 & $\mathrm{~kg} / \mathrm{ha}$ \\
\hline 2 & & $7 / 30 / 14$ & Harvest & Winter wheat & 7400 & $\mathrm{~kg} / \mathrm{ha}$ \\
\hline 2 & & $8 / 8 / 14$ & Soil cultivation & Chisel; depth $20 \mathrm{~cm}$ & NA & NA \\
\hline 2 & & $9 / 11 / 14$ & Soil cultivation & Plow, depth $25-30 \mathrm{~cm}$ & NA & NA \\
\hline 2 & & $9 / 24 / 14$ & Planting & Winter barley & 160 & $\mathrm{~kg} / \mathrm{ha}$ \\
\hline 4 & \multirow{11}{*}{$11,24,25,26,28,29,31$} & $7 / 30 / 14$ & Harvest & Straw left on field (mulching) & 3500 & $\mathrm{~kg} / \mathrm{ha}$ \\
\hline 4 & & $7 / 30 / 14$ & Harvest & Winter wheat & 7600 & $\mathrm{~kg} / \mathrm{ha}$ \\
\hline 4 & & $8 / 7 / 14$ & Soil cultivation & Chisel; depth $20 \mathrm{~cm}$ & NA & NA \\
\hline 4 & & $9 / 17 / 14$ & Soil cultivation & Plow, depth $25-30 \mathrm{~cm}$ & NA & NA \\
\hline 4 & & $9 / 21 / 14$ & Planting & Winter barley & 160 & $\mathrm{~kg} / \mathrm{ha}$ \\
\hline 9 & & $11 / 18 / 13$ & Soil cultivation & Plow, depth $25-30 \mathrm{~cm}$ & NA & NA \\
\hline 9 & & $3 / 21 / 14$ & Soil cultivation & Harrow & NA & NA \\
\hline 9 & & $4 / 4 / 14$ & Planting & Maize & 85000 & Seeds/ha \\
\hline 9 & & $9 / 5 / 14$ & Harvest & Maize & 16900 & $\mathrm{~kg} / \mathrm{ha}$ \\
\hline 9 & & $10 / 5 / 14$ & Soil cultivation & Mulch application & NA & NA \\
\hline 9 & & $10 / 16 / 14$ & Soil cultivation & Plow, depth $25-30 \mathrm{~cm}$ & NA & NA \\
\hline 10 & \multirow{11}{*}{23} & $7 / 20 / 14$ & Harvest & Wheat & 10.1 & t/ha \\
\hline 10 & & $7 / 30 / 14$ & Planting & Kresse & 2 & $\mathrm{~kg} / \mathrm{ha}$ \\
\hline 10 & & $7 / 30 / 14$ & Planting & Phacelia & 3 & $\mathrm{~kg} / \mathrm{ha}$ \\
\hline 10 & & $7 / 30 / 14$ & Planting & Clover & 5 & $\mathrm{~kg} / \mathrm{ha}$ \\
\hline 10 & & $7 / 30 / 14$ & Planting & Buekwheat & 15 & $\mathrm{~kg} / \mathrm{ha}$ \\
\hline 10 & & $11 / 17 / 14$ & Soil Cultivation & Plow, depth $25-30 \mathrm{~cm}$ & NA & NA \\
\hline 14 & & $7 / 28 / 14$ & Harvest & Winter wheat & 6300 & $\mathrm{~kg} / \mathrm{ha}$ \\
\hline 14 & & $7 / 28 / 14$ & Harvest & Straw left on field (mulching) & NA & NA \\
\hline 14 & & $8 / 2 / 14$ & Soil cultivation & Grubber; depth $15 \mathrm{~cm}$ & NA & NA \\
\hline 14 & & $8 / 14 / 14$ & Planting & Phacelia & 15 & $\mathrm{~kg} / \mathrm{ha}$ \\
\hline 14 & & $11 / 18 / 14$ & Soil cultivation & Chisel, depth $25-30 \mathrm{~cm}$ & NA & NA \\
\hline 15 & \multirow{7}{*}{$20,21,22$} & $3 / 7 / 14$ & Soil cultivation & Harrow & NA & NA \\
\hline 15 & & $4 / 1 / 14$ & Soil cultivation & Harrow & NA & NA \\
\hline 15 & & $4 / 15 / 14$ & Planting & Maize & 90000 & Seeds/ha \\
\hline 15 & & $10 / 10 / 14$ & Harvest & Maize & 12380 & $\mathrm{~kg} / \mathrm{ha}$ \\
\hline 15 & & $10 / 13 / 14$ & Soil cultivation & Plow, depth $25-30 \mathrm{~cm}$ & NA & NA \\
\hline 15 & & $10 / 14 / 14$ & Soil cultivation & Harrow & NA & NA \\
\hline 15 & & $10 / 20 / 14$ & Planting & Winter wheat & 180 & $\mathrm{~kg} / \mathrm{ha}$ \\
\hline 16 & \multirow{4}{*}{6} & $7 / 28 / 14$ & Harvest & Wheat & 6300 & $\mathrm{~kg} / \mathrm{ha}$ \\
\hline 16 & & $8 / 2 / 14$ & Soil cultivation & Harrow & NA & NA \\
\hline 16 & & $8 / 14 / 14$ & Planting & Phacelia & 15 & $\mathrm{~kg} / \mathrm{ha}$ \\
\hline 16 & & $11 / 19 / 14$ & Soil cultivation & Plow, depth $25-30 \mathrm{~cm}$ & NA & NA \\
\hline 17 & \multirow{7}{*}{8} & $3 / 13 / 14$ & Soil cultivation & Harrow & NA & NA \\
\hline 17 & & $5 / 21 / 14$ & Harvest & Meadow & NA & NA \\
\hline 17 & & $8 / 6 / 14$ & Harvest & Meadow & NA & NA \\
\hline 19 & & $7 / 1 / 14$ & Harvest & Rapeseed & 4600 & $\mathrm{~kg} / \mathrm{ha}$ \\
\hline 19 & & $8 / 10 / 14$ & Planting & Phacelia & 25 & $\mathrm{~kg} / \mathrm{ha}$ \\
\hline 27 & & 7/7/14 & Harvest & Rapeseed & 4500 & $\mathrm{~kg} / \mathrm{ha}$ \\
\hline 29 & & $7 / 7 / 14$ & Harvest & Rapeseed & 4500 & $\mathrm{~kg} / \mathrm{ha}$ \\
\hline
\end{tabular}


carbon water content equivalent can be estimated from onsite soil chemistry sampling as

$$
\theta_{\mathrm{SOC}_{\mathrm{eq}}}=(\mathrm{TC}-\mathrm{TIC}) * 1.725 * f_{\mathrm{WE}},
$$

where TC is the soil total carbon $(\mathrm{g} / \mathrm{g})$, TIC is the inorganic carbon determined by measuring $\mathrm{CO}_{2}$ after the sample is acidified $(\mathrm{g} / \mathrm{g}), 1.724$ is a constant to convert total organic carbon into total organic matter, and $f_{\mathrm{WE}}=0.494$ is the stoichiometric ratio of $\mathrm{H}_{2} \mathrm{O}$ to organic carbon (assuming organic carbon is cellulose $\mathrm{C}_{6} \mathrm{H}_{10} \mathrm{O}_{5}$ ) [32].

From grid sampling at $50 \mathrm{~m}$ resolutions, [21] found the study site had an average clay weight fraction of $0.20(\mathrm{~g} / \mathrm{g})$, thus yielding $\theta_{\mathrm{LW}}=0.02 \mathrm{~g} / \mathrm{g}$ by using regression analyses from a catalog of lattice water samples and clay weight fractions $(0.03$ to $0.38 \mathrm{~g} / \mathrm{g}$ ) from across the globe (Franz unpublished data). We estimated the study site had $\theta_{\mathrm{SOC}}=$ $0.005 \mathrm{~g} / \mathrm{g}$ using a $1 \mathrm{~km}$ global SOC product [33], noting that local samples are also available [21] but vary widely with land use practice. Lastly, we found from direct sampling at the site on December 12, 2013, the dry soil bulk density was $1.43 \mathrm{~g} / \mathrm{cm}^{3}$, with a standard deviation of $0.091 \mathrm{~g} / \mathrm{cm}^{3}$, from 61 samples. We note that in agricultural landscapes bulk density may vary significantly across land use and time depending on routine practices. Future work with the CRNP in agricultural settings should address how bulk density changes through time and with land use.

\section{Results and Discussion}

4.1. Spatiotemporal Variation of Time-Domain Transmissivity Soil Water Content. The time series of daily average SWC between December 2013 and September 2014 for all 16 TDT sites organized by depth are illustrated in Figure 3. Because of varying planting, soil cultivation, and harvest date, TDT profiles from different land use parcels were removed at different dates (Table 1). The TDT probes were later reinserted but the data was not available for the entire time period. Therefore, we restricted our main analyses between December 12, 2013, and May 1, 2014, when 12 of the 16 sites were all available. Figure 3 illustrates the wide range of expected SWC that occur at all 3 measured depths across the various land uses. Figure 4 illustrates the landscape average mean SWC of all sensors by depth, \pm 1 standard error of the mean, and \pm 1 standard deviation. The key points drawn from the TDT network are as follows: (1) relative changes of TDT response to rainfall across sites are consistent, (2) estimates of the landscape SWC are uncertain $\left(\sim 0.02 \mathrm{~m}^{3} / \mathrm{m}^{3}\right.$ standard error of the mean and $0.07 \mathrm{~m}^{3} / \mathrm{m}^{3}$ standard deviation for range of SWC and all soil depths), (3) absolute values of SWC for a single site are not representative of the landscape SWC for all depths, and (4) comparison of TDT values for individual sites within a single land use parcel (i.e., S11, 24, 25, 26, 28, 29, and 31 within L4 and S20, 21, and 22 within L15) show a similarly wide range of variability as all TDT sites within the study area. The wide spatial variability of SWC at this site is reported elsewhere using higher density TDR surveys (see Figure 12 in [21]).

The observation that a single sensor behaves consistently against the landscape average is consistent with the concept of temporal stability $[34,35]$ and the ability of the site to be representative of the landscape average. However, this landscape average is not known a priori and requires either a network of sensors to establish how good the mean is (here we found an average of 16 sensors gave a standard error of the mean as $\sim 0.02 \mathrm{~m}^{3} / \mathrm{m}^{3}$ ) or repeated but labor-intensive field campaigns with a portable system such as a TDR. The observation that the intra-land use SWC variability was similar to the inter-land use SWC variability was consistent with other direct point sensor work in agriculture [36] and has relevance to using characteristics like vegetation type, structure, or leaf area index to select a small number of representative point sensor locations [37]. Due to the fractal nature of SWC fields [14] and the expected variance at all length scales [38], point sensors with a small support volume $\left(\sim 0.01 \mathrm{~m}^{3}\right)$ that are located relatively close together $(\sim 2 \mathrm{~m})$ may still exhibit very different absolute SWC values due to the natural variation that exists. This implies that the practice of removal and replacement of point sensors following normal production activities can be challenging to recreate a similar SWC response to rainfall, thus requiring a new calibration and new temporal stability analysis to justify the representativeness of the point sensor against the landscape SWC.

4.2. Temporal Variation of Cosmic-Ray Neutron Probe Soil Water Content. Figure 5 illustrates the time series of daily rainfall and moderated neutron counts at the study site. We notice the corrected moderated counts decrease sharply with precipitation and increase slowly following an exponential shape. Using 1 gravimetric calibration and 2 TDR calibrations we estimated $N_{0}$ using (1). The gravimetric campaign consisted of averaging 61 individual samples, by collecting samples at 3 depths $(0-5,5-10$, and $15-20 \mathrm{~cm})$ for 16 locations (where the TDT are located) on December 12, 2013, yielding $N_{0}=1494.7 \mathrm{cph}$. The TDR campaign consisted of sampling the 16 TDT site locations using a portable device with $15 \mathrm{~cm}$ rod lengths inserted vertically from the surface. The TDR calibrations yielded $N_{0}=1453.0 \mathrm{cph}$ on April 5, 2014, and $N_{0}=$ $1441.1 \mathrm{cph}$ on April 30, 2014. The average $N_{0}=1462.9 \mathrm{cph}$ was used to convert moderated neutron counts into SWC for the entire time period. Figure 6 illustrates the time series of daily average SWC from the CRNP, landscape average TDT from different depths, $0-20 \mathrm{~cm}$ landscape average TDT, and SWC from the $3 \mathrm{Grav} / \mathrm{TDR}$ calibration dates $(0-20 \mathrm{~cm}$ and 0-15 cm, resp.).

In this work we did not consider any influence of vegetation on the neutron counts given the wide variety of crop types, different timing of planting and harvesting (Table 1), and expected relatively low landscape average fresh standing biomass $\left(<2 \mathrm{~kg} / \mathrm{m}^{2}\right)$. For a discussion of the effects of vegetation (i.e., mass changes in above-ground hydrogen) on the expected neutron counts, we refer the reader elsewhere [39-41]. Moreover, given the small changes of $N_{0}$ values for the 3 different calibration dates ( $\pm 26 \mathrm{cph}$ or $1.8 \%$ difference), we found the effects of vegetation on neutron count were likely small for this environment given the accuracy of the gravimetric calibration datasets themselves (standard error of 


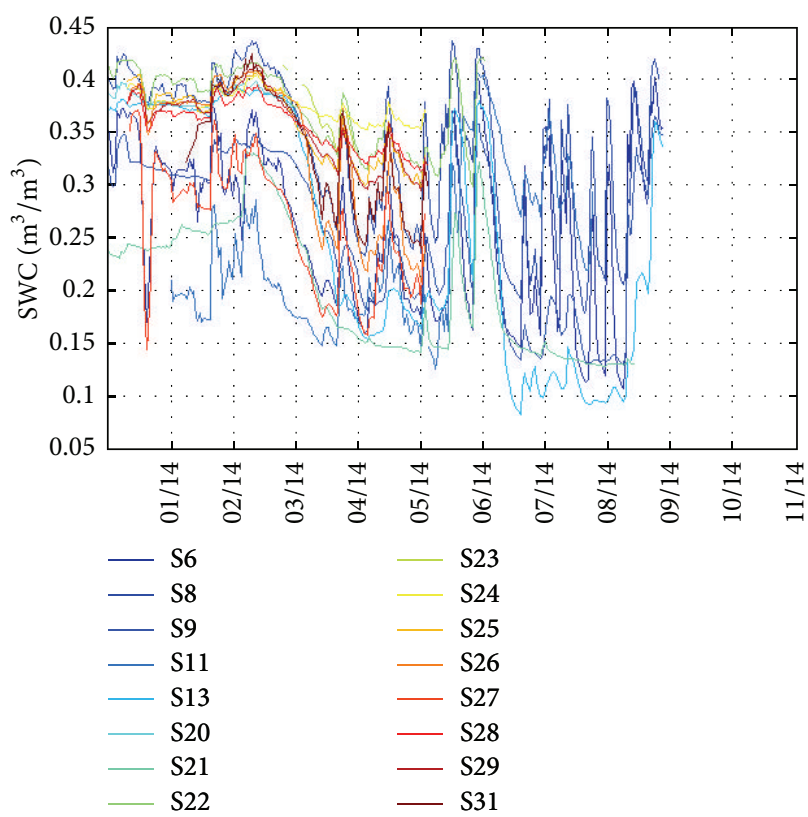

(a) Depth $0-5 \mathrm{~cm}$

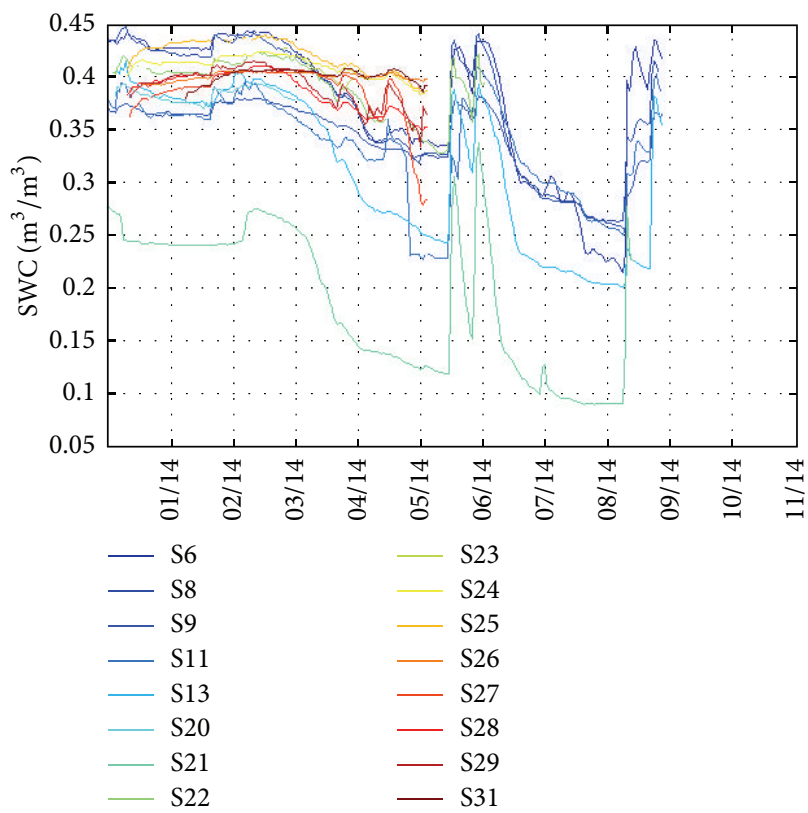

(c) Depth $15-20 \mathrm{~cm}$

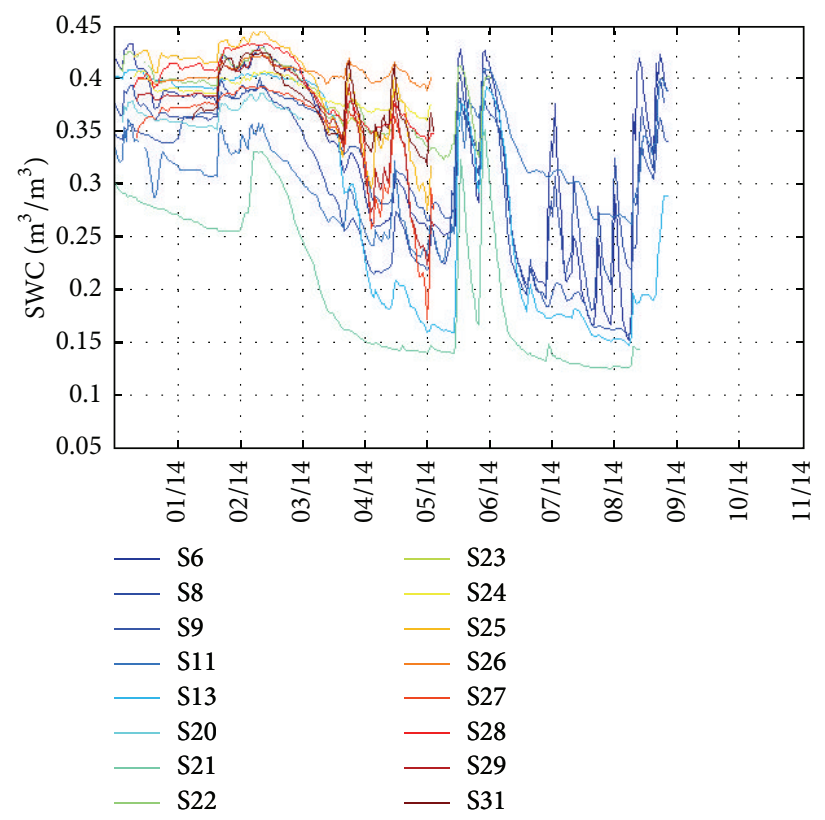

(b) Depth $5-10 \mathrm{~cm}$

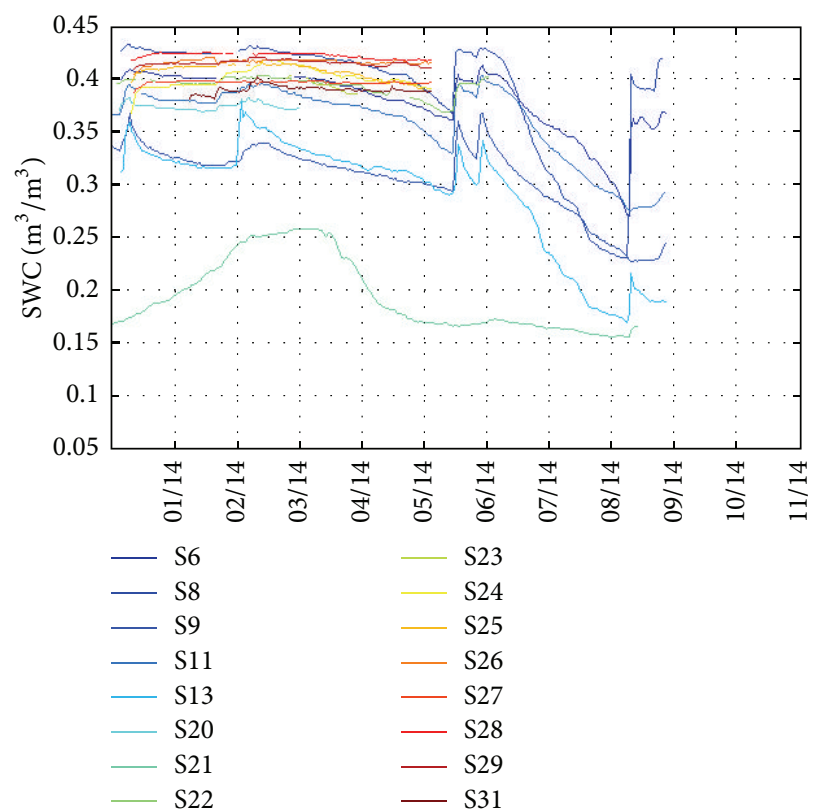

(d) Depth $45-50 \mathrm{~cm}$

FIGURE 3: Time series of TDT probes organized by depth (a-d) and by site location illustrating the wide range of SWC encountered. All TDT sensors were installed in mid-December 2013 but removed over time on different dates due to the various soil cultivation and harvest times of each of the land use parcels. TDT sensors were reinserted over time as part of the HOAL experiment [21].

mean $\left.\pm 0.02 \mathrm{~m}^{3} / \mathrm{m}^{3}\right)$. Finally, the recommendation of using a minimum of 3 calibration sampling dates at different water contents to estimate $N_{0}$ was reported elsewhere [42] and is based on neutron particle transport modeling and an error propagation analysis. For best practices, we recommend a minimum of 3 gravimetric calibration periods to estimate $N_{0}$ in agricultural environments.
4.3. Comparison of Landscape Soil Water Content. In Figure 6, we find that the CRNP compares well against the independent TDT network observations given the standard error of the mean at $\pm 0.02 \mathrm{~m}^{3} / \mathrm{m}^{3}$ for the TDT landscape average. Most importantly, the CRNP and shallow TDT sensors all respond to precipitation (Figure 5(a)) and decrease at similar rates. Table 2 summarizes a comparison 


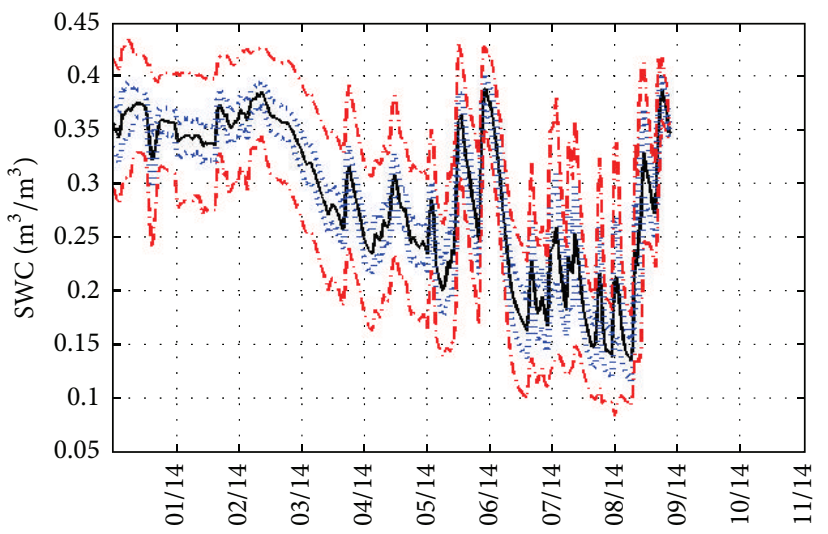

- Mean \pm 1 S.E. of mean

(a) Depth $0-5 \mathrm{~cm}$

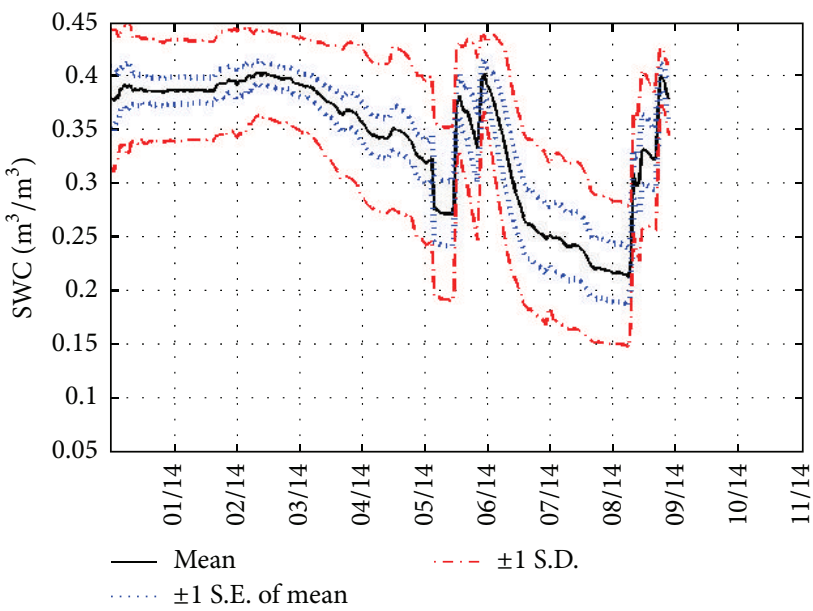

(c) Depth $15-20 \mathrm{~cm}$

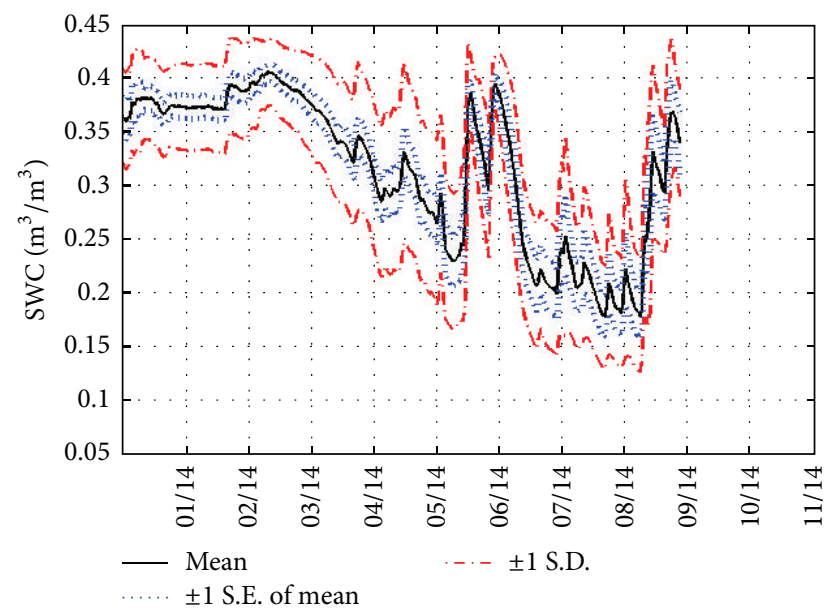

(b) Depth 5-10 cm

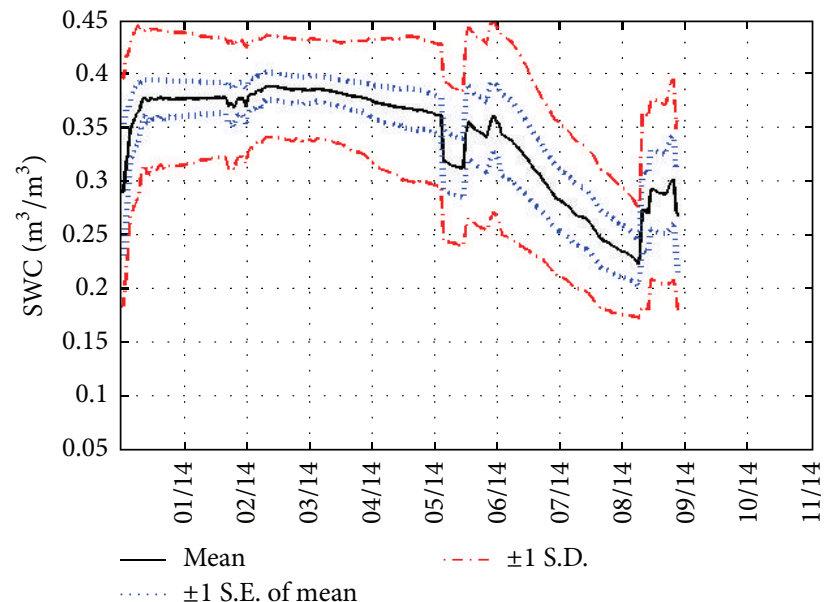

(d) Depth $45-50 \mathrm{~cm}$

FIGURE 4: Time series of site mean SWC, standard error of the mean, and standard deviation organized by depth (a-d). Note that the number of probes for each depth changes through time because of different soil cultivation and harvest dates of the various land use parcels.

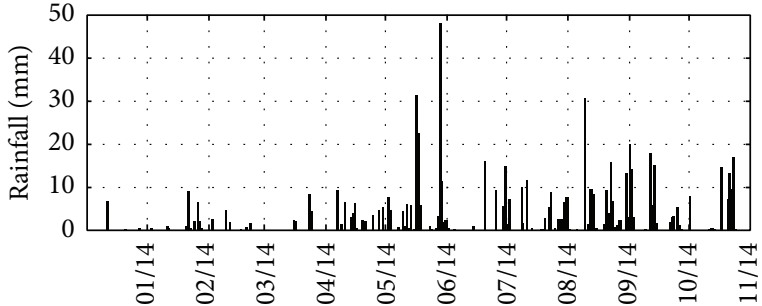

(a)

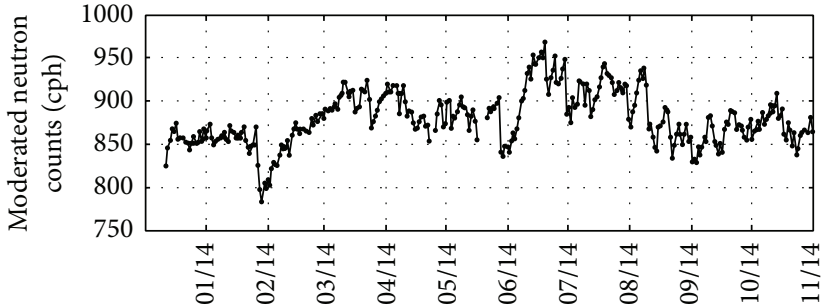

(b)

Figure 5: Time series of (a) daily rainfall $(\mathrm{mm})$ and $(\mathrm{b})$ corrected moderated neutron counts at the study site. Note: snow was present on the ground at the site between January 27 and February 3, 2014, causing the large fluctuation in the moderated count.

between the 3 TDT and Grav/TDR calibration dates, and estimation of landscape SWC using the CRNP and various calibration datasets. The analysis is based on the spatial averaging and error analysis presented elsewhere [37]. Reference [37] describes 9 different sampling strategies and error estimates for 3 different study sites around the globe. Here we find that the mean absolute error (MAE) of the landscape average SWC between the 3 TDT and Grav/TDR sampling campaigns is $0.0229 \mathrm{~m}^{3} / \mathrm{m}^{3}$ (Table 2). Table 2 also summarizes a cross calibration analysis of the CRNP if individual calibration dates using either TDT or Grav/TDR are used. For a single calibration of $N_{0}$, we find that the estimates of SWC from the CRNP can vary widely for different sampling dates (range: -0.074 to 
TABLE 2: (Top section) Summary of the spatial average SWC from the TDT network and Grav/TDR from the 3 calibration sample dates. The daily average neutron count and computed $N_{0}$ values (using (1)) are also reported. Note that only 12 TDT sites (i.e., 6, 8, 9, 13, 21, 22, 24, 25, 26, 27,28 , and 29) were used in the spatial average SWC, whereas all 16 sites were used in the Grav/TDR average. The mean absolute error of the spatial average SWC between the TDT and Grav/TDR methods for the three sample dates is $0.0229 \mathrm{~m}^{3} / \mathrm{m}^{3}$. (Middle section) Estimation of spatial average SWC from the CRNP using the $N_{0}$ values computed from the 3 TDT and Grav/TDR calibration sample dates. The individual $N_{0}$ 's are used to cross-estimate the SWC between sample the 3 sample dates. In addition, the spatial average SWC is estimated for each date using the average of the $3 N_{0}$ values. (Lower section) Difference between spatial average SWC and the CRNP estimated value for all 3 sample dates and each method. The mean absolute error using the average $N_{0}$ value for each calibration method is reported as $0.0255 \mathrm{~m}^{3} / \mathrm{m}^{3}$ for the TDT network and $0.0209 \mathrm{~m}^{3} / \mathrm{m}^{3}$ for the Grav/TDR sampling. The mean absolute error using the average $N_{0}$ from Grav/TDR sampling versus the TDT values is reported as $0.0286 \mathrm{~m}^{3} / \mathrm{m}^{3}$.

\begin{tabular}{|c|c|c|c|c|c|c|}
\hline & \multicolumn{3}{|c|}{ TDT $(0-20 \mathrm{~cm})$} & \multicolumn{3}{|c|}{ Grav/TDR $(0-15 \mathrm{~cm})$} \\
\hline & \multicolumn{6}{|c|}{ Sample date } \\
\hline & $12 / 12 / 13$ & $4 / 5 / 14$ & $4 / 30 / 14$ & $12 / 12 / 13$ & $4 / 5 / 14$ & $4 / 30 / 14$ \\
\hline Spatial avg. SWC $\left(\mathrm{m}^{3} / \mathrm{m}^{3}\right)$ & 0.3795 & 0.2885 & 0.2829 & 0.3947 & 0.2448 & 0.2926 \\
\hline Daily avg. neutrons (cph) & 846.3 & 917.8 & 874.0 & 846.3 & 917.8 & 874.0 \\
\hline Daily avg. $N_{0}(\mathrm{cph})$ & 1481.4 & 1508.4 & 1430.0 & 1494.7 & 1453.0 & 1441.1 \\
\hline $\begin{array}{l}\text { MAE SWC }\left(\mathrm{m}^{3} / \mathrm{m}^{3}\right) \text {, TDT versus } \\
\text { Grav/TDR }\end{array}$ & 0.0229 & & & & & \\
\hline \multicolumn{7}{|c|}{ Spatial avg. SWC from CRNP $\left(\mathrm{m}^{3} / \mathrm{m}^{3}\right)$} \\
\hline Using $N_{0,1}$ & & 0.2666 & 0.3299 & & 0.2772 & 0.3430 \\
\hline Using $N_{0,2}$ & 0.4109 & & 0.3569 & 0.3488 & & 0.3033 \\
\hline Using $N_{0,3}$ & 0.3254 & 0.2280 & & 0.3365 & 0.2360 & \\
\hline Using avg. $N_{0}$ & 0.3705 & 0.2602 & 0.3221 & 0.3593 & 0.2523 & 0.3124 \\
\hline \multicolumn{7}{|c|}{ Difference in spatial avg. SWC $\left(\mathrm{m}^{3} / \mathrm{m}^{3}\right)$, TDT versus CRNP and Grav/TDR versus CRNP } \\
\hline Using $N_{0,1}$ & & 0.0219 & -0.0470 & & -0.0324 & -0.0504 \\
\hline Using $N_{0,2}$ & -0.0314 & & -0.0740 & 0.0459 & & -0.0107 \\
\hline Using $N_{0,3}$ & 0.0541 & 0.0605 & & 0.0582 & 0.0088 & \\
\hline Using avg. $N_{0}$ & 0.0090 & 0.0283 & -0.0392 & 0.0354 & -0.0075 & -0.0198 \\
\hline $\begin{array}{l}\text { MAE SWC }\left(\mathrm{m}^{3} / \mathrm{m}^{3}\right) \text {, using avg. } \\
N_{0}\end{array}$ & 0.0255 & & & 0.0209 & & \\
\hline $\begin{array}{l}\text { MAE SWC }\left(\mathrm{m}^{3} / \mathrm{m}^{3}\right) \text {, using avg. } \\
N_{0} \text { of Grav/TDR versus TDT } \\
\text { values }\end{array}$ & 0.0286 & & & & & \\
\hline
\end{tabular}

$\left.0.0582 \mathrm{~m}^{3} / \mathrm{m}^{3}\right)$. However, when 3 calibration dates are used to estimate $N_{0}$, we find the range is much narrower $(-0.0392$ to $0.0354 \mathrm{~m}^{3} / \mathrm{m}^{3}$ ), with MAE $=0.0255 \mathrm{~m}^{3} / \mathrm{m}^{3}$ for the TDT data, and $0.0209 \mathrm{~m}^{3} / \mathrm{m}^{3}$ for the Grav/TDR samples. Finally, the MAE of the CRNP data using the 3 Grav/TDR calibration datasets versus the independent TDT data is $0.0286 \mathrm{~m}^{3} / \mathrm{m}^{3}$. The reduction of error depending on single versus multiple calibration and absolute versus dynamic calibration, and the number of points used in the spatial average is consistent with the findings in [37]. Given the continued investment into the HOAL experiment [21], we expect future work to more fully describe the various sources of instrument and averaging error.

In terms of the absolute SWC comparison between the Grav/TDR calibrations and the TDT data, we find that the $\mathrm{MAE}=0.0286 \mathrm{~m}^{3} / \mathrm{m}^{3}$ is comparable to other studies in various natural ecosystems (mixed montane forest [43], semiarid shrubland [44], and deciduous forests in the eastern USA [39] and Germany [31]) and is on the same order of magnitude as the TDT sensors averaged by depth (Figure 4). The difference between the methods are likely due in part to differences between the TDT factory calibration and local field conditions, uncertainty in the CRNP observations, and natural variability due to spatial averaging heterogeneous environments. Overall the comparison between the TDT network average and CRNP was within acceptable error of $<0.04 \mathrm{~m}^{3} / \mathrm{m}^{3}$ used in validating remote sensing products against ground observations $[45,46]$.

\section{Conclusions}

In this work, we present a comparison of landscape SWC values between a CRNP and independent TDT sensor network in a mixed agricultural land use system in northeast Austria. Routine agricultural production practices of soil cultivation, planting, and harvest make the operation and maintenance of direct contact point sensor networks challenging. Here, the CRNP footprint consisted of 12 different land use parcels with a mixture of winter and summer crops. From the 3 gravimetric/TDR calibration dates, we found relatively small changes $(1.8 \%)$ of $N_{0}$ due to the different land uses and vegetation conditions for this mixed agricultural system. This is consistent with other studies that found minimal changes of vegetation $\left(<2 \mathrm{~kg} / \mathrm{m}^{2}\right)$ on expected neutron counts. After using the average $N_{0}$ from the 3 gravimetric/TDR calibration datasets, we find the MAE 


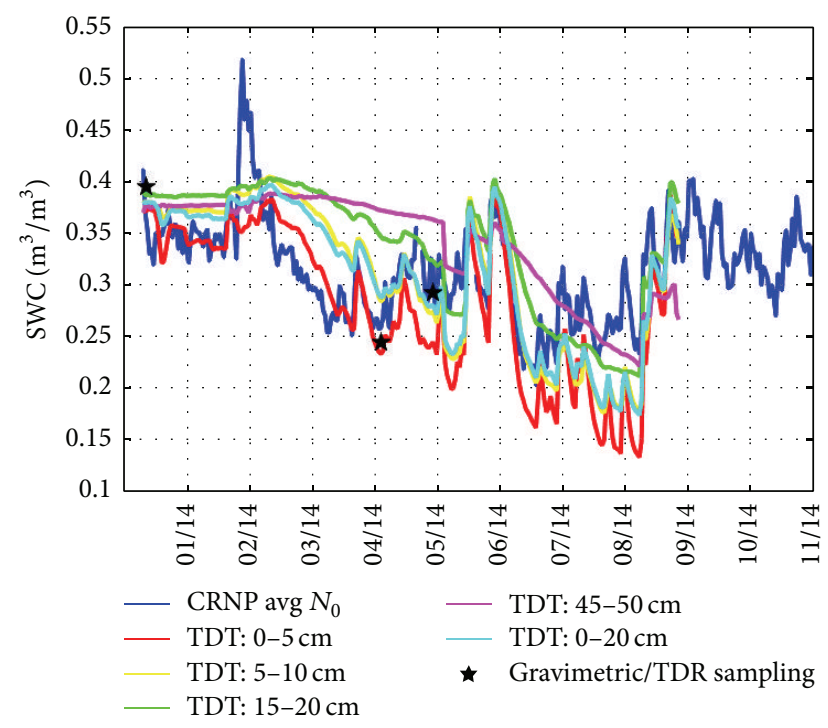

FIgURE 6: Time series of site average independent SWC TDT values by depth, SWC from the CRNP using the average $N_{0}$ from (1) gravimetric calibration campaign (December 12, 2013) and (2) TDR calibration campaigns (April 5 and 30, 2014). The gravimetric campaign consisted of averaging 61 individual samples, by collecting samples at 3 depths $(0-5,5-10$, and $15-20 \mathrm{~cm})$ for 16 locations (where the permanent TDT are located; Figure 2(b)). The TDR campaign consisted of sampling the same 16 locations (where the permanent TDT are located; Figure 2(b)) using a portable device with $15 \mathrm{~cm}$ rod lengths. The TDR rods were inserted vertically and a minimum of 3 repeated measures were used to make an average for each of the 16 sites.

of $0.0286 \mathrm{~m}^{3} / \mathrm{m}^{3}$ between the CRNP and the independent TDT network is on the same order of magnitude as other studies in natural ecosystems, within the uncertainty for wellestablished SWC point sensors $\left( \pm 0.02 \mathrm{~m}^{3} / \mathrm{m}^{3}\right.$ standard error of mean), and within the $0.04 \mathrm{~m}^{3} / \mathrm{m}^{3}$ recommendation used in validating remote sensing SWC products against ground observations. For best practice using CNRP, we recommend a minimum of 3 calibration datasets at different wetness levels to estimate $N_{0}$ instead of relying on a single calibration dataset. Moreover, additional calibration datasets could be used to confirm or locally establish the other three calibration function coefficients given in (1). Because the CRNP can be placed out of the way of routine production practices, we see it as a more suitable method for establishing long-term SWC monitoring in agricultural settings or used in irrigation applications. The ability of the CRNP to provide real-time and accurate landscape SWC measurements in agricultural ecosystems make it an ideal method for aiding in agricultural water and nutrient management decisions at the parcel level as well as aiding in management decisions at larger scales.

\section{Conflict of Interests}

Darin Desilets is coowner of HydroInnova LLC. HydroInnova is the only company that commercially produces the cosmic-ray neutron probe. The remaining authors declare that there is no conflict of interests regarding the publication of this paper.

\section{Authors' Contribution}

Trenton E. Franz and Ammar Wahbi equally share authorship.

\section{Acknowledgment}

Trenton E. Franz would like to acknowledge the support of the Daugherty Water for Food Institute at the University of Nebraska.

\section{References}

[1] M. Jung, M. Reichstein, P. Ciais et al., "Recent decline in the global land evapotranspiration trend due to limited moisture supply," Nature, vol. 467, no. 7318, pp. 951-954, 2010.

[2] R. D. Koster, P. A. Dirmeyer, Z. Guo et al., "Regions of strong coupling between soil moisture and precipitation," Science, vol. 305, no. 5687, pp. 1138-1140, 2004.

[3] S. I. Seneviratne, T. Corti, E. L. Davin et al., "Investigating soil moisture-climate interactions in a changing climate: a review," Earth-Science Reviews, vol. 99, no. 3-4, pp. 125-161, 2010.

[4] J. A. Santanello Jr., C. D. Peters-Lidard, and S. V. Kumar, "Diagnosing the sensitivity of local land-atmosphere coupling via the soil moisture-boundary layer interaction," Journal of Hydrometeorology, vol. 12, no. 5, pp. 766-786, 2011.

[5] L. S. Dingman, Physical Hydrology, Prentice-Hall, Upper Saddle River, NJ, USA, 2nd edition, 2002.

[6] T. W. Ford and S. M. Quiring, "Comparison and application of multiple methods for temporal interpolation of daily soil moisture," International Journal of Climatology, vol. 34, no. 8, pp. 2604-2621, 2014.

[7] T. W. Ford and S. M. Quiring, "In situ soil moisture coupled with extreme temperatures: a study based on the Oklahoma Mesonet," Geophysical Research Letters, vol. 41, no. 13, pp. 47274734, 2014.

[8] E. D. Hunt, M. Svoboda, B. Wardlow, K. Hubbard, M. Hayes, and T. Arkebauer, "Monitoring the effects of rapid onset of drought on non-irrigated maize with agronomic data and climate-based drought indices," Agricultural and Forest Meteorology, vol. 191, pp. 1-11, 2014.

[9] R. M. Iverson, "Landslide triggering by rain infiltration," Water Resources Research, vol. 36, no. 7, pp. 1897-1910, 2000.

[10] K. A. Johnson and N. Sitar, "Hydrologic conditions leading to debris-flow initiation," Canadian Geotechnical Journal, vol. 27, no. 6, pp. 789-801, 1990.

[11] D. A. Robinson, C. S. Campbell, J. W. Hopmans et al., "Soil moisture measurement for ecological and hydrological watershedscale observatories: a review," Vadose Zone Journal, vol. 7, no. 1, pp. 358-389, 2008.

[12] W. T. Crow, A. A. Berg, M. H. Cosh et al., "Upscaling sparse ground-based soil moisture observations for the validation of coarse-resolution satellite soil moisture products," Reviews of Geophysics, vol. 50, no. 2, Article ID RG2002, 2012.

[13] A. W. Western and G. Blöschl, "On the spatial scaling of soil moisture," Journal of Hydrology, vol. 217, no. 3-4, pp. 203-224, 1999. 
[14] I. Rodriguez-Iturbe, G. K. Vogel, R. Rigon, D. Entekhabi, F. Castelli, and A. Rinaldo, "On the spatial organization of soil moisture fields," Geophysical Research Letters, vol. 22, no. 20, pp. 2757-2760, 1995.

[15] D. J. Greenwood, K. Zhang, H. W. Hilton, and A. J. Thompson, "Opportunities for improving irrigation efficiency with quantitative models, soil water sensors and wireless technology," Journal of Agricultural Science, vol. 148, no. 1, pp. 1-16, 2010.

[16] S. Irmak, J. M. Rees, G. L. Zoubek et al., "Nebraska agricultural water management demonstration network (NAWMDN): integrating research and extension/outreach," Applied Engineering in Agriculture, vol. 26, no. 4, pp. 599-613, 2010.

[17] D. A. Robinson, A. Binley, N. Crook et al., "Advancing processbased watershed hydrological research using near-surface geophysics: a vision for, and review of, electrical and magnetic geophysical methods," Hydrological Processes, vol. 22, no. 18, pp. 3604-3635, 2008.

[18] M. Zreda, D. Desilets, T. P. A. Ferré, and R. L. Scott, "Measuring soil moisture content non-invasively at intermediate spatial scale using cosmic-ray neutrons," Geophysical Research Letters, vol. 35, no. 21, Article ID L21402, 2008.

[19] M. Zreda, W. J. Shuttleworth, X. Zeng et al., "COSMOS: the cosmic-ray soil moisture observing system," Hydrology and Earth System Sciences, vol. 16, no. 11, pp. 4079-4099, 2012.

[20] A. Hawdon, D. McJannet, and J. Wallace, "Calibration and correction procedures for cosmic-ray neutron soil moisture probes located across Australia," Water Resources Research, vol. 50, no. 6, pp. 5029-5043, 2014.

[21] G. Bloschl, A. P. Blaschke, M. Broer et al., "The Hydrological Open Air Laboratory (HOAL) in Petzenkirchen: a hypothesisdriven observatory," Hydrology and Earth System Sciences, vol. 20, no. 1, pp. 227-255, 2016.

[22] S. R. Evett and J. L. Steiner, "Precision of neutron scattering and capacitance type soil water content gauges from field calibration," Soil Science Society of America Journal, vol. 59, no. 4, pp. 961-968, 1995.

[23] W. Gardner and D. Kirkham, "Determination of soil moisture by neutron scattering," Soil Science, vol. 73, no. 5, pp. 391-402, 1952.

[24] D. Desilets, M. Zreda, and T. P. A. Ferré, "Nature's neutron probe: land surface hydrology at an elusive scale with cosmic rays," Water Resources Research, vol. 46, Article ID W11505, 2010.

[25] S. Glasstone and M. C. Edlund, Elements of Nuclear Reactor Theory, Van Nostrand, New York, NY, USA, 1952.

[26] D. Desilets, Sandia Report: SAND2011-1101, Radius of Influence for a Cosmic-Ray Soil Moisture Probe: Theory and Monte Carlo Simulations, Sandia National Laboratories, Albuquerque, NM, USA, 2011.

[27] D. Desilets and M. Zreda, "Footprint diameter for a cosmic-ray soil moisture probe: theory and monte carlo simulations," Water Resources Research, vol. 49, no. 6, pp. 3566-3575, 2013.

[28] M. Köhli, M. Schrön, M. Zreda, U. Schmidt, P. Dietrich, and S. Zacharias, "Footprint characteristics revised for field-scale soil moisture monitoring with cosmic-ray neutrons," Water Resources Research, vol. 51, no. 7, pp. 5772-5790, 2015.

[29] T. E. Franz, M. Zreda, T. P. A. Ferre et al., "Measurement depth of the cosmic-ray soil moisture probe affected by hydrogen from various sources," Water Resources Research, vol. 48, no. 8, 2012.

[30] R. Rosolem, W. J. Shuttleworth, M. Zreda et al., "The effect of atmospheric water vapor on the cosmic-ray soil moisture signal," Journal of Hydrometeorology, vol. 14, no. 5, pp. 16591671, 2013.

[31] H. R. Bogena, J. A. Huisman, R. Baatz, H.-J. Hendricks Franssen, and H. Vereecken, "Accuracy of the cosmic-ray soil water content probe in humid forest ecosystems: the worst case scenario," Water Resources Research, vol. 49, no. 9, pp. 57785791, 2013.

[32] D. W. Nelson and L. E. Sommers, "Total carbon, organic carbon, and organic matter," in Methods of Soil Analysis, Part 2, A. L. Page, Ed., pp. 961-1010, American Society of Agronomy, 2nd edition, 1996.

[33] W. Shangguan, Y. Dai, Q. Duan, B. Liu, and H. Yuan, "A global soil data set for earth system modeling," Journal of Advances in Modeling Earth Systems, vol. 6, no. 1, pp. 249-263, 2014.

[34] M. H. Cosh, T. J. Jackson, S. Moran, and R. Bindlish, “Temporal persistence and stability of surface soil moisture in a semi-arid watershed," Remote Sensing of Environment, vol. 112, no. 2, pp. 304-313, 2008.

[35] G. Vachaud, A. Passerat De Silans, P. Balabanis, and M. Vauclin, "Temporal stability of spatially measured soil-water probability density-function," Soil Science Society of America Journal, vol. 49, no. 4, pp. 822-828, 1985.

[36] C. B. Hedley and I. J. Yule, "A method for spatial prediction of daily soil water status for precise irrigation scheduling," Agricultural Water Management, vol. 96, no. 12, pp. 1737-1745, 2009.

[37] A. J. Teuling, R. Uijlenhoet, F. Hupet, E. E. van Loon, and P. A. Troch, "Estimating spatial mean root-zone soil moisture from point-scale observations," Hydrology and Earth System Sciences, vol. 10, no. 5, pp. 755-767, 2006.

[38] B. B. Mandelbrot, "Stochastic models for the Earth's relief, the shape and the fractal dimension of the coastlines, and the number-area rule for islands," Proceedings of the National Academy of Sciences of the United States of America, vol. 72, no. 10, pp. 3825-3828, 1975.

[39] E. J. Coopersmith, M. H. Cosh, and C. S. T. Daughtry, "Fieldscale moisture estimates using COSMOS sensors: a validation study with temporary networks and Leaf-Area-Indices," Journal of Hydrology, vol. 519, pp. 637-643, 2014.

[40] T. E. Franz, M. Zreda, R. Rosolem et al., "Ecosystem-scale measurements of biomass water using cosmic ray neutrons," Geophysical Research Letters, vol. 40, no. 15, pp. 3929-3933, 2013.

[41] D. McJannet, T. Franz, A. Hawdon et al., "Field testing of the universal calibration function for determination of soil moisture with cosmic-ray neutrons," Water Resources Research, vol. 50, no. 6, pp. 5235-5248, 2014.

[42] J. Iwema, R. Rosolem, R. Baatz, T. Wagener, and H. R. Bogena, "Investigating temporal field sampling strategies for site-specific calibration of three soil moisture-neutron intensity parameterisation methods," Hydrology and Earth System Sciences, vol. 19, no. 7, pp. 3203-3216, 2015.

[43] L. Lv, T. E. Franz, D. A. Robinson, and S. B. Jones, "Measured and modeled soil moisture compared with cosmic-ray neutron probe estimates in a mixed forest," Vadose Zone Journal, vol. 13, no. 12, pp. 1-13, 2014.

[44] T. E. Franz, M. Zreda, R. Rosolem, and T. P. A. Ferre, "Field validation of a cosmic-ray neutron sensor using a distributed sensor network," Vadose Zone Journal, vol. 11, no. 4, 2012.

[45] D. Entekhabi, E. G. Njoku, P. E. O’Neill et al., “The soil moisture active passive (SMAP) mission," Proceedings of the IEEE, vol. 98, no. 5, pp. 704-716, 2010. 
[46] Y. H. Kerr, P. Waldteufel, J.-P. Wigneron et al., "The SMOS mission: new tool for monitoring key elements of the global water cycle," Proceedings of the IEEE, vol. 98, no. 5, pp. 666-687, 2010. 

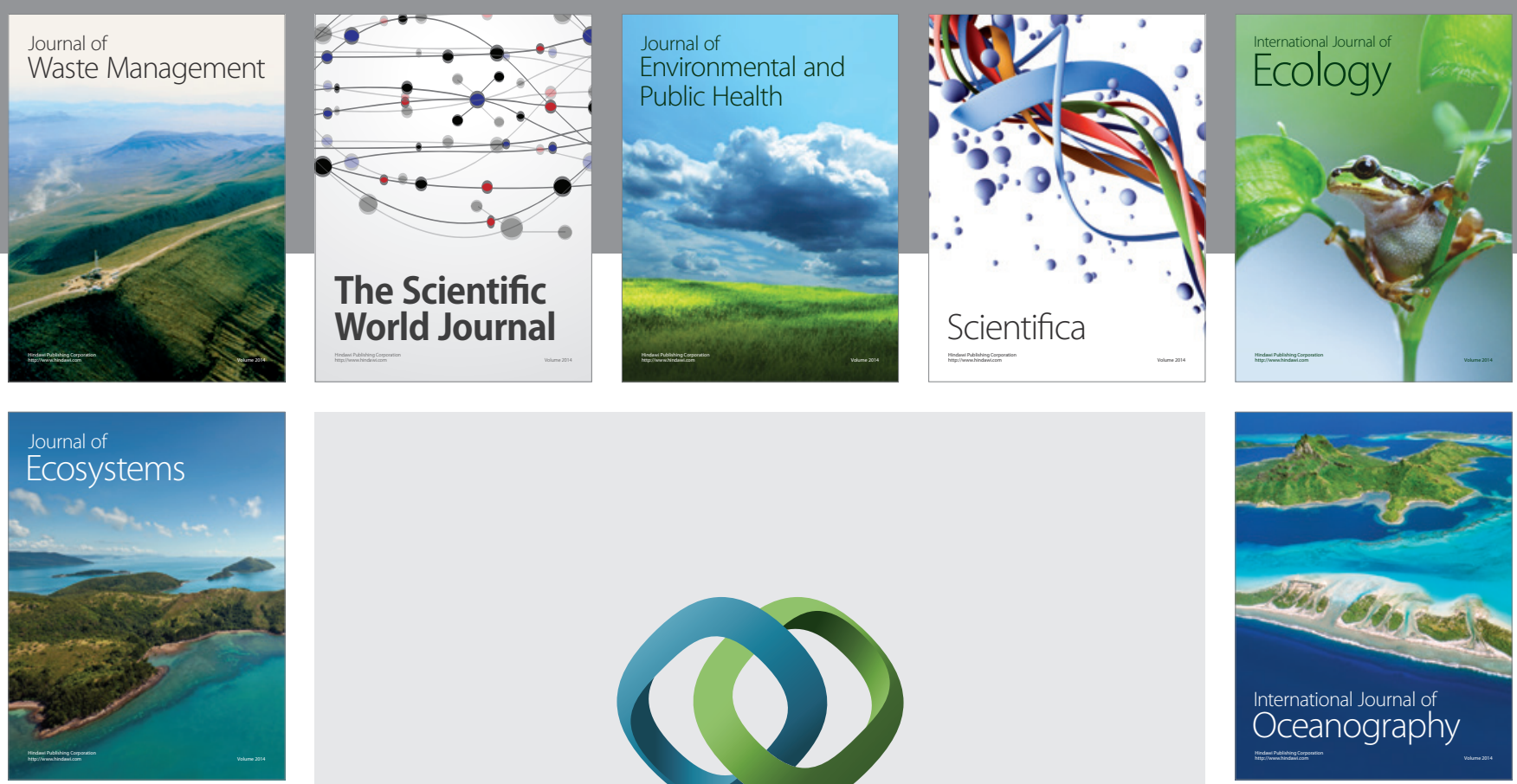

The Scientific World Journal
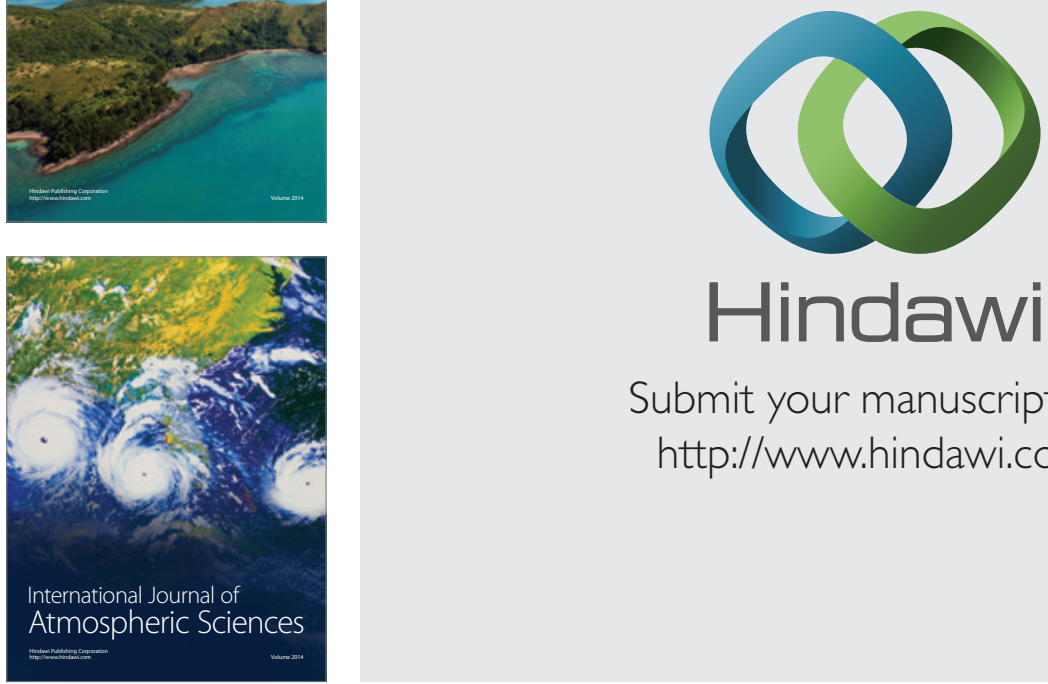

\section{Hindawi}

Submit your manuscripts at

http://www.hindawi.com
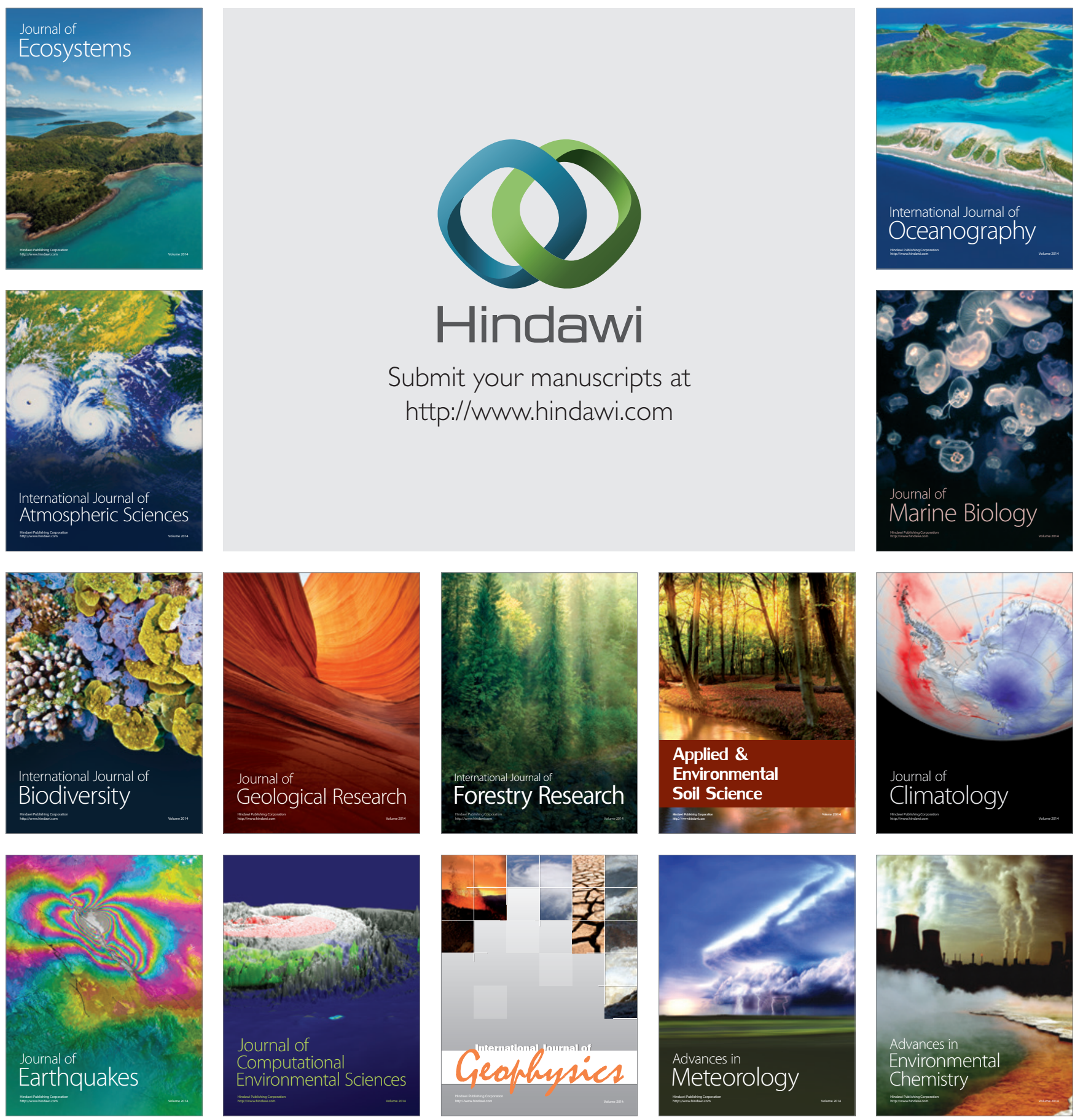